\title{
CAPÍTULO 01: QUALIDADE E EFICIÊNCIA DE TRANSFORMAÇÃO DO LEITE CRU EM QUEIJO: UM ESTUDO DE CASO EM UM LATICÍNIO NO ESTADO DO AMAZONAS
}

\section{CAPÍTULO 01: CALIDAD Y EFICIENCIA EN EL PROCESAMIENTO DE LECHE CRUDA EN QUESO: UN ESTUDIO DE CASO EN UN PRODUCTO LÁCTEO EN EL ESTADO DE AMAZONIA}

\section{CHAPTER 01: QUALITY AND EFFICIENCY IN PROCESSING RAW MILK INTO CHEESE: A CASE STUDY IN A DAIRY PRODUCT IN THE STATE OF AMAZON}

\author{
Terezinha Teixeira de Souza ${ }^{1}$; Gean Augusto Pereira Mendonça ${ }^{1}$; Jailton Ribeiro Dos Santos Junior ${ }^{2}$; Vanessa \\ Rocha da Conceição ${ }^{2}$; Denise Ribeiro de Freitas ${ }^{3}$
}

DOI: https://doi.org/10.31692/978-65-88970-18-8.1-20

\begin{abstract}
RESUMO
A falta de informações sobre a qualidade do leite produzido em Parintins-AM dificulta o desenvolvimento de indústrias laticinistas, uma vez que as mesmas precisam de matéria-prima de qualidade para alcançar um bom rendimento de seus produtos. Dessa forma, a caracterização da qualidade do leite torna-se indispensável tanto para a indústria quanto para os produtores de leite. Diante disso, esse trabalho foi realizado com o objetivo de avaliar a qualidade e a eficiência de transformação do leite cru em queijo Minas Frescal e queijo de Coalho processados em um laticínio do Amazonas. As amostras de leite, soro e queijo foram coletadas em um laticínio no Município de Parintins, e submetidas a análises físico-química (proteína, gordura, extrato seco total e desengordurado, lactose, cinzas, matéria gorna no extrato seco total, acidez, $\mathrm{pH}$ e densidade) e microbiológica (contagem bacteriana total). Para avaliação das perdas de proteína e gordura foi considerado a composição centesimal do leite e do soro, quanto aos rendimentos econômico e ajustado foram calculados com base no volume total do leite e o peso estimado de cada lote dos queijos. O coeficiente GL foi feito com base na composição centesimal do queijo. Os dados foram submetidos a análise estatística descritiva. Com base nos parâmetros avaliados para o leite cru de cada produtor, o resultado para extrato seco desengordurado esteve fora do padrão mínimo estabelecido e $45 \%$ das amostras avaliadas para contagem bacteriana total não atendiam a legislação vigente. Quanto ao rendimento de fabricação de ambos os queijos avaliados foram tecnicamente rentáveis, isso mostra que o leite utilizado na produção dos queijos atendia os requisitos mínimos de qualidade.
\end{abstract}

Palavras-Chave: Minas Frescal, Parintins, Queijo de Coalho.

\section{RESUMEN}

La falta de información sobre la calidad de la leche producida en Parintins-AM dificulta el desarrollo de las industrias lácteas, ya que necesitan materia prima de calidad para lograr un buen rendimiento de sus productos. Así, la caracterización de la calidad de la leche se vuelve fundamental tanto para la industria como para los productores de leche. Por ello, este trabajo se realizó con el objetivo de evaluar la calidad y eficiencia de la transformación de la leche cruda en queso Minas Frescal y queso Coalho procesados en una lechería en Amazonas. Las muestras de leche, suero y queso fueron recolectadas en una quesería del municipio de Parintins, y sometidas a análisis físico-químico (proteína, grasa, extracto seco total y desgrasado, lactosa, ceniza, grasa en el extracto seco total, acidez, $\mathrm{pH}$ y densidad) y microbiológico (recuento bacteriano total). Para evaluar la pérdida de proteínas y grasas se consideró la composición próxima de la leche y el suero, y se calcularon los rendimientos económicos y ajustados con base en el volumen total de leche y el peso estimado de cada lote de quesos. El coeficiente GL se basó en la

\footnotetext{
${ }^{1}$ Discente na Universidade Federal do Amazonas Campus - Parintins, teka_tsouza05@hotmail.com

${ }^{1}$ Discente na Universidade Federal do Amazonas Campus - Parintins, geanaugusto1029@gmail.com

${ }^{2}$ Discente na Universidade Federal de Sergipe, juniorribeirodossantos@ hotmail.com

${ }^{2}$ Discente na Universidade Federal de Sergipe, vivianerocha760@ gmsil.com

${ }^{3}$ Docente na Universidade Federal de Sergipe Campus do Sertão, deniseribeirof@academico.ufs.br
} 


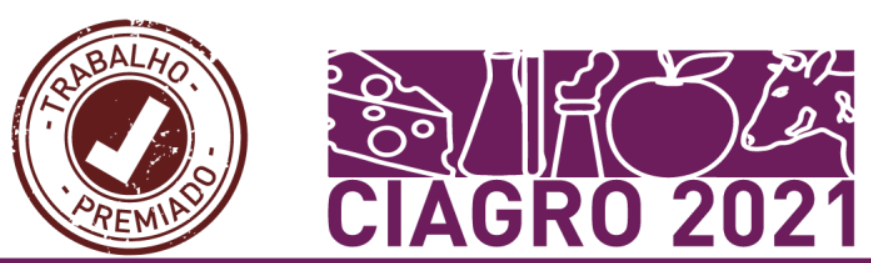

composición química del queso. Los datos se sometieron a análisis estadístico descriptivo. Con base en los parámetros evaluados para la leche cruda de cada productor, el resultado del extracto seco desgrasado estuvo fuera del estándar mínimo establecido y el $45 \%$ de las muestras evaluadas para el recuento bacteriano total no cumplió con la legislación vigente. En cuanto a que los rendimientos de producción de ambos quesos evaluados fueron técnicamente rentables, esto demuestra que la leche utilizada en la elaboración de quesos cumplió con los requisitos mínimos de calidad.

Palabras Clave: Minas Frescal, Parintins, Queso Coalho.

\section{ABSTRACT}

The lack of information about the quality of the milk produced in Parintins-AM makes the development of dairy industries difficult, since they need quality raw material to achieve a good yield of their products. Thus, the characterization of milk quality becomes essential both for the industry and for milk producers. Therefore, this work was carried out with the objective of evaluating the quality and efficiency of the transformation of raw milk into Minas Frescal cheese and Coalho cheese processed in a dairy in Amazonas. Milk, whey and cheese samples were collected in a dairy in the municipality of Parintins, and subjected to physicochemical analysis (protein, fat, total and defatted dry extract, lactose, ash, fat in the total dry extract, acidity, $\mathrm{pH}$ and density) and microbiological (total bacterial count). To evaluate the loss of protein and fat, the proximate composition of milk and whey was considered, and the economic and adjusted yields were calculated based on the total volume of milk and the estimated weight of each batch of cheeses. The GL coefficient was based on the chemical composition of the cheese. Data were subjected to descriptive statistical analysis. Based on the parameters evaluated for raw milk from each producer, the result for defatted dry extract was outside the established minimum standard and $45 \%$ of the samples evaluated for total bacterial count did not meet current legislation. As for the production yield of both evaluated cheeses were technically profitable, this shows that the milk used in the production of cheeses met the minimum quality requirements.

Keywords: Minas Frescal, Parintins, Coalho Cheese.

\section{INTRODUÇÃO}

A produção de leite no Amazonas, assim como os seus derivados são produzidos de forma incipiente, pois em sua maioria são desenvolvidos em pequenas propriedades rurais. Sendo estas localizadas em ecossistemas bastante adversos, como os sistemas de várzea e terrafirme. Dessa forma, dificultando a logística de transporte do leite diariamente até o centro urbano, onde estão localizadas as indústrias de laticínios. Diante dessas condições, uma parte dos proprietários optam por produzir seu próprio produto de forma artesanal e comercializá-los semanalmente, no entanto, essa escala de produção não supre a demanda do comércio local e estadual. Assim, a maioria dos produtos lácteos consumidos no Estado do Amazonas são importados de outros estados do Brasil.

O conhecimento da qualidade físico-química e microbiológica do leite define diversas propriedades sensoriais e industriais da produção de queijo, além de permitir a detecção de falhas nas práticas de manejo e serve como referência na valorização da matéria-prima pelos laticínios (MELO, 2013). Portanto, o leite deve ser monitorado na plataforma da recepção de laticínios, para garantir a saúde da população e um bom rendimento dos queijos.

O rendimento de fabricação e a composição do queijo são determinados pelas 


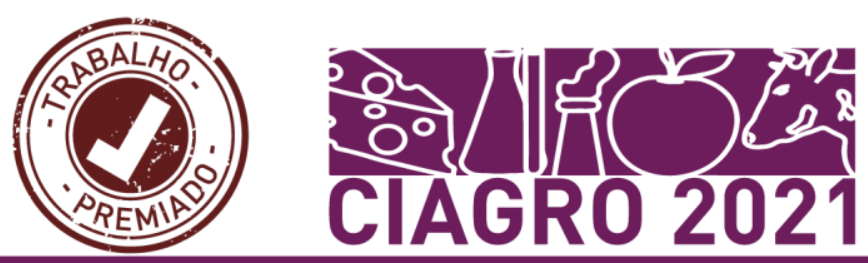

propriedades do leite e pelas etapas do processamento de fabricação. Portanto, é indispensável

à avaliação da composição físico-química do leite para a fabricação de queijos, pois é de importância para a uniformidade do produto final (RAMOS, 2013).

A falta de informações sobre a qualidade do leite produzido em Parintins-AM dificulta o desenvolvimento de indústrias laticinistas, uma vez que as mesmas precisam de matéria-prima de qualidade para alcançar um bom rendimento de seus produtos. A caracterização da qualidade do leite é indispensável tanto para a indústria quanto para os produtores de leite, visto que pode facilitar o controle da produção de queijos e garantir um produto final de qualidade, podendo agregar valor á matéria-prima e aumentar a rentabilidade do produtor, e com isso, a indústria poderá pagar o leite por sua composição nutricional e não apenas por volume. Diante disso o principal objetivo deste trabalho foi avaliar a qualidade e a eficiência de transformação do leite cru em queijo Minas Frescal e queijo de Coalho processados em um laticínio do Amazonas.

\section{FUNDAMENTAÇÃO TEÓRICA}

\section{Produção de leite no Amazonas}

O Brasil ocupa a quarta posição no ranking mundial de produção de leite, atrás apenas dos Estados Unidos, Índia e China (FAO, 2013). Entre os estados brasileiros, o maior produtor de leite é Minas Gerais. O estado do Amazonas, produziu 2.692 litors de leite no quarto trimestre de 2020. (IBGE, 2020). Segundo Farias (2008), o leite produzido no Amazonas, em sua maioria é destinado à fabricação de queijos dentro das próprias propriedades leiteiras. Isso deve-se ao fato da produção de leite ser baixa, uma vez que a maioria das propriedades criam animais de dupla aptidão, ou seja, leite e carne, e com isso, o leite produzido só consegue atender a demanda interna da propriedade.

Outro fator limitante da comercialização do leite nessa região é o sistema (várzea e terrafirme) em que esses animais estão inseridos, pois a produção de leite só acontece na várzea, que corresponde a um período de oito meses, o qual coincide com a disponibilidade das pastagens nativas (MOTA et al., 2012). Além desses fatores, o leite produzido na região do Baixo Amazonas é pouco valorizado por sua qualidade, pois poucas propriedades investem em manejo nutricional e de ordenha, sendo que a maioria das propriedades ainda produz em sistemas tradicionais. Normalmente, a nutrição não é especializada e o sistema de ordenha é realizado sem nenhuma prática básica de higiene, o que favorece aos problemas sanitários com animal (MOTA et al., 2012). 
Nesse contexto, os problemas relacionados com a baixa produção e qualidade do leite, tem sido um dos entraves para implantação de laticínios nessa região, uma vez que o mesmo precisa de matéria-prima de qualidade, e o ano todo.

\section{Qualidade físico-química do leite}

A qualidade do leite pode ser evidenciada por meio de determinação físico-químicas, provas de higiene, reações colorimétricas e provas sensoriais. Por meio dessas análises, é possível identificar a adição de substâncias adulterantes ou eventual presença de substâncias conservantes (TRONCO, 2008).

Dentre as diversas análises físico-químicas que são realizadas no controle de qualidade do leite, podem-se citar a de gordura, proteínas, extrato seco total (EST), extrato seco desengordurado (ESD), lactose, densidade e acidez (TRONCO, 2008). Todas essas análises devem seguir os padrões mínimos e máximos exigidos pela Instrução Normativa $\mathrm{N}^{\circ} 76$ e 77/2018. Os procedimentos para realização das análises pode ser individualmente, seguindo seus respectivos métodos, ou com ajuda de equipamentos eletrônicos que podem avaliar vários parâmetros de uma só vez.

Segundo a Instrução Normativa No 76 e 77, de 26 de novembro de 2018, entende-se por leite, sem outra especificação, o produto oriundo da ordenha completa e ininterrupta, em condições de higiene, de vacas sadias, bem alimentadas e descansadas (BRASIL, 2018).

O leite é rico em nutrientes essências para alimentação humana. No entanto, essa riqueza nutricional também torna esse alimento susceptível ao desenvolvimento de microrganismos patogênicos, que podem causar alterações físico-químicas e organolépticas, com isso limitando sua durabilidade e de seus derivados, e consequentemente, ocasionando problemas econômicos e de saúde pública (MACHADO et al., 2012).

A qualidade do leite é influenciada principalmente por fatores relacionados à nutrição animal, fatores genéticos, sanidade e manejo de ordenha. Sendo que, os dois últimos fatores são decisivos na cadeia produtiva de leite, uma vez que, a falta de higienização durante o processo de ordenha, elevados índices de mastite, manutenção e desinfecção inadequada dos equipamentos e a refrigeração ineficiente ou inexistente podem ocasionar problemas microbiológicos, e consequentemente, físico-químicos no leite (SANTANA et al., 2001).

\section{Qualidade microbiológica do leite}

O leite por ter uma composição completa e balanceada torna-se um ambiente propício 


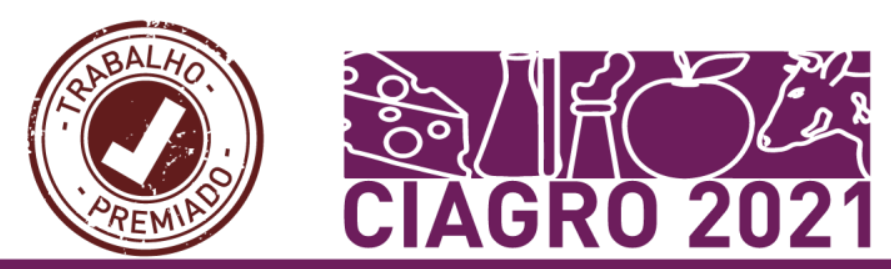

para o desenvolvimento de diversos microrganismos, sendo as bactérias o principal grupo que possui maior representatividade (TRONCO, 2008). Muitas dessas bactérias são psicrotróficas, ou seja, conseguem se reproduzir tanto em baixas (menor que $7^{\circ} \mathrm{C}$ ), quanto em altas temperaturas, produzindo enzimas lipolíticas e proteolíticas que afetarão a qualidade do leite e a vida útil de seus derivados (SANTOS e FONSECA, 2007).

Segundo Furtado (2005), a temperatura de armazenamento do leite é um dos principais fatores que determina a multiplicação e desenvolvimento de microrganismos do leite. Temperaturas baixas podem inibir ou reduzir esses microrganismos, além de reduzir também, a atividade de enzimas degradativas. Por isso, aconselha-se o uso da refrigeração desde o momento da ordenha (ARCURI et al., 2006). No entanto, o tempo prolongado de armazenagem em temperaturas de refrigeração favorece o crescimento e o predomínio de bactérias psicrotróficas.

A pasteurização do leite não é totalmente eficiente para eliminação de todos os microrganismos, pois existem das bactérias chamadas termodúricas, que são capazes de produzir enzimas lipolíticas e proteolíticas que mantem suas atividade enzimática após a pasteurização (SANTOS e FONSECA, 2007).

Entre as diversas análises dos parâmetros microbiológicos do leite, está à contagem bacteriana total (contagem de mesófilos), umas das análises mais importantes para garantir a qualidade microbiológica do leite. Seus resultados devem esta conforme a os requisitos exigidos pela IN 76, que preconiza um valor máximo de $900.000 \mathrm{UFC} / \mathrm{ml}$ para o leite cru refrigerado antes de seu processamento na unidade beneficiadora (BRASIL, 2018).

Contagem bacteriana total acima dos limites tolerados pela legislação é um indicativo de falhas na limpeza e higienização dos equipamentos de ordenha e do sistema de refrigeração (TRONCO, 2008).

Para quantificar essas bactérias presente no leite, faz-se necessária a realização de algumas técnicas, como, análise de contagem padrão em placas, que é um método tradicional descrito pela Instrução Normativa $\mathrm{N}^{\circ} 76$, porém eficiente, pois o mesmo serve de base para os testes mais modernos, como aqueles realizados por citometria de fluxo que consiste na medição de características celulares das células suspensas em meio fluido. Ambos os teste expressão seus resultados em UFC/mL.

\section{Queijo Minas Frescal}

O queijo Minas Frescal é de origem brasileira e amplamente produzido e consumido em 


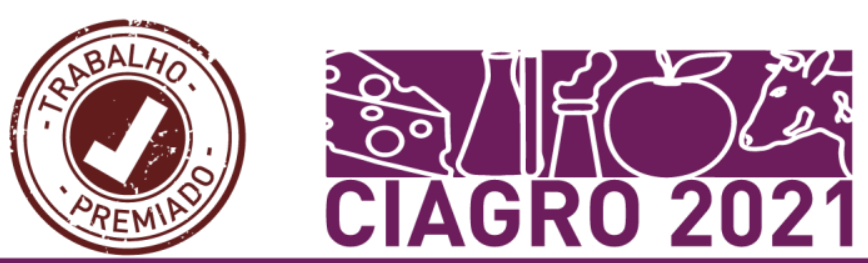

todo o território nacional, pois é um produto de grande aceitação no mercado, tecnologia de processamento acessível e bom rendimento de fabricação, o que atrai o interesse das indústrias queijeiras (PASSOS et al., 2009). É um queijo fresco obtido por coagulação enzimática do leite com coalho e/ou outras enzimas coagulantes apropriadas, completamente ou não com ação de bactérias láticas especificas (BRASIL, 1996).

Segundo a Instrução Normativa $N^{\circ}$ 04/2004, o queijo Minas Frescal é classificado como um queijo semi-gordo (25 a 44\% de MGEST), alta umidade (igual ou maior que 55\%), com consistência branda e macia, com ou sem olhaduras mecânicas, de cor esbranquiçada, de sabor suave e levemente ácido. É um queijo não curado, podendo ser consumido fresco, e deve ser armazenados em temperaturas não superiores a $8{ }^{\circ} \mathrm{C}$ e embalados em embalagens plásticas ou acondicionadas em embalagens bromatologicamente aptas.

\section{Queijo de Coalho}

O queijo de coalho é um queijo amplamente difundido e fabricado na Região Norte e Nordeste. É um queijo que se obtêm por coagulação do leite por meio do coalho ou outras enzimas coagulantes apropriadas, complementada ou não pela ação de bactérias lácteas selecionadas e comercializado normalmente com até 10 (dez) dias de fabricação. É um queijo de média $(36,0-45,9 \%)$ a alta umidade $(46,0-54,9 \%)$, de massa semi-cozida ou cozida e apresentando um teor de gordura nos sólidos totais variáveis entre 35,0\% e 60,0\% (BRASIL, 2001).

O queijo de coalho apresenta uma consistência semidura e elástica com textura compacta e macia podendo apresentar algumas olhaduras. Apresenta cor branca amarelada uniforme, sabor brando, ligeiramente ácido, podendo ser salgado, com aroma, também ligeiramente ácido, que lembra massa de queijo coagulada (BRASIL, 2001). Este produto é muito consumido, seja na forma natural, assado, como também muito utilizado em preparações culinárias, sendo, atualmente, muito difundido em toda região brasileira (NASSU et al., 2006).

\section{Rendimento de fabricação}

O rendimento de fabricação de queijo é amplamente utilizado e monitorado constantemente nas indústrias queijeiras, podendo ser avaliado de duas maneiras: por meio de rendimento econômico e rendimento técnico (FURTADO, 2005). O rendimento econômico é o volume em litros de leite necessários para fabricar um quilograma de determinado tipo de queijo, levando em consideração o preço pago por um litro de leite. Com base nesse rendimento, 


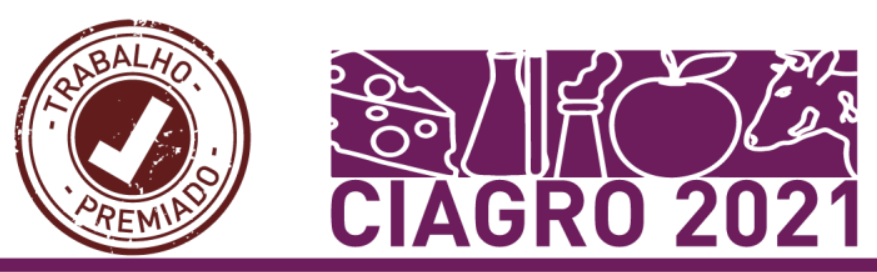

o empresário consegue estimar o custo final da produção de queijo no laticínio (FURTADO, 2005).

O rendimento técnico, por sua vez, é aquele obtido por meio de dados sobre a composição físico-química do leite, do soro e do queijo, e a partir desses dados o empresário conseguir determinar o quanto dos constituintes do leite foi aproveitado no queijo produzido. Entretanto, o rendimento técnico pode ser expresso de varias forma, desde estimativas mais simples até as mais complexas. Dentre eles pode-se citar as perdas dos constituintes no soro, rendimento ajustado para um mesmo teor de umidade e coeficiente G/L (FURTADO, 2005).

As perdas de gordura e/ou de proteínas no soro é um método relativamente simples que necessita apenas dos teores de gordura e proteína do leite e do soro, e com isso, calcula-se a proporção perdida da seguinte forma: teor em percentagem da gordura ou proteína do soro dividido pela percentagem da gordura ou proteína do leite, tudo isso vezes 100. Ressalta-se que, esse método serve apenas de referência quando aplicado sempre ao mesmo tipo de queijo, feito na mesma técnica e com o mesmo volume de leite (FURTADO, 2005).

Segundo Furtado (2005), por mais que se tenha um controle da qualidade do leite e do processo de fabricação, é muito difícil obter queijos de diferentes lotes de produção com a mesma composição físico-química. Destaca ainda, que isso dificulta a comparação do índice de rendimento dentro de uma produção. Para isso, faz-se necessário ajustar o rendimento dos queijos para um mesmo teor de umidade.

$\mathrm{O}$ rendimento em gramas de sólitos totaisT/quilo de leite utilizado ( $\mathrm{ST} / \mathrm{Kg}$ ) ou o coeficiente G/L é um parâmetro que demostra a eficiência do processo em termos de aproveitamento dos componentes nutricionais do leite no queijo. Nesse parâmetro busca-se determinar a quantidade de sólidos totais presente nos queijos, em gramas, por litro de leite utilizado na fabricação. Sua determinação é importante, pois a composição físico-química do queijo pode variar em função da composição do leite ou pelas etapas de fabricação do queijo, como corte, mexedura, dessoragem, etc. (FURTADO, 2005).

Vários fatores podem influenciar no rendimento industrial (econômico ou técnico), dentre eles pode-se destacar a composição nutricional do leite, a pasteurização do leite, tipos de ingredientes usados, as perdas durante o corte da massa, contagem de células somáticas e de bactérias psicrotróficas no leite cru (FURTADO, 2005; CARDOSO, 2006). Dessa forma, para produzir um queijo com rendimento satisfatório para a industrial faz-se necessário conhecer as propriedades da matéria-prima que será utilizado na produção (CARDOSO, 2006). 


\section{Local do estudo}

Este trabalho foi desenvolvido em um laticínio, localizado no Município de Parintins, Região do Baixo Amazonas.

O laticínio possui Serviço de Inspeção Estadual (SIE), processa diariamente cerca de 600 litros de leite, proveniente de propriedades localizadas próximas da cidade. O leite é destinado ao processamento de iogurte, queijo Minas Frescal e queijo de Coalho.

Durante o período de coleta desse estudo foi contabilizado 10 produtores que forneciam o leite diariamente para o laticínio. O leite de cada produtor era armazenado em galões de plástico e transportado até laticínio por meio de embarcações fluviais e de motocicletas.

\section{Composição físico-química do leite cru}

Foram realizadas 42 coletas para análises físico-químicas do leite de cada produtor. As determinações do teor de gordura, proteína, extrato seco total e extrato seco desengordurado, lactose e cinzas, foram realizadas através de um analisador de leite eletrônico (MASTER COMPLETE $^{\circledR}$ ) calibrado com amostras de leite de composição conhecida, de acordo com o manual do fabricante. As análises de acidez em ${ }^{\circ}$ Dornic e densidade a $20^{\circ} \mathrm{C}$ foram realizadas de acordo com os métodos citados pela Instrução Normativa $N^{\circ} 76$ (BRASIL, 2018). Todas essas análises foram realizadas no laboratório do laticínio.

\section{Contagem bacteriana total (CBT) do leite cru}

Foram coletadas 4 amostras de leite cru de cada produtor durante quatro semanas, sendo uma por semana. As amostras foram coletadas em recipiente estéril diretamente dos galões de leite depois de homogeneizado, e posteriormente foram acondicionadas e transportadas em caixas isotérmicas até o Laboratório de Microbiologia da Universidade Federal do Amazonas, Campus de Parintins. As amostras foram armazenadas em geladeira e analisadasno mesmo dia - As amostras foram analisadas de acordo com as recomendações citada pela Instrução Normativa No 62 do Ministério da Agricultura Pecuária e Abastecimento (BRASIL, 2003).

\section{Composições físico-químicas do queijo, do leite e do soro}

Foram avaliados dez lotes de queijos, sendo cinco de queijo Minas Frescal e cinco de 


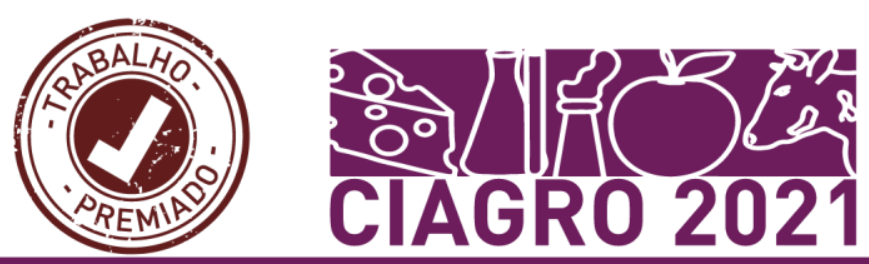

queijo de Coalho. Foram utilizados 300 litros de leite para cada produção, com exceção de uma produção do queijo Minas Frescal que foi utilizado 224 litros.

De cada produção, foram coletadas amostras representativas de leite cru do tanque de fabricação e amostras do soro produzido após o corte da coalhada durante o processo de produção do queijo. As amostras de leite cru e o soro foram acondicionados em frascos com tampas rosqueáveis, enquanto que as peças de queijos foram embaladas a vácuo no próprio laticínio. Todas as amostras foram identificadas e transportadas em caixa isotérmicas para o Laboratório de Bromatologia da Universidade Federal do Amazonase posteriormente congeladas até a realização das análises.

As análises físico-químicas realizadas nas amostras de leite cru, soro e queijo foram: proteína pelo método Kjeldahl, com o fator 6,38 multiplicado pela porcentagem de nitrogênio; gordura pelo método butirométricos (Gerber); extrato seco total, extrato seco desengordurado obtido a partir do cálculo da diferença entre os percentuais de extrato seco total e gordura, segundo a fórmula: $\mathrm{ESD}=(\% \mathrm{EST}-\%$ Gordura $) ;$ matéria gorda no extrato seco total (MGEST) determinado a partir do cálculo da razão entre os percentuais de gordura e extrato seco total, expresso em porcentagem, segundo a fórmula: MGEST $=($ Gordura/EST $)$ x 100 e cinzas. A acidez foi determinada em ácido lático, e o pH foi mensurado com um pHmetro de bolso portátil (Kasvi), previamente calibrado. Todas as análises foram determinadas de acordo com os métodos oficias preconizado pela legislação vigente (BRASIL, 2018).

\section{Rendimentos de fabricação e perdas dos nutrientes}

Para estabelecer o rendimento de fabricação foi necessário medir o volume total de leite e pesar $20 \%$ do total das peças de queijo de cada produção, sendo que cada peça pesava aproximadamente $500 \mathrm{~g}$. E com isso foi possível estimar o peso $(\mathrm{Kg})$ total dos lotes de queijos.

Para calcular as perdas de gordura e proteína no soro foi considerada a composição centesimal do leite e do soro.

O rendimento de fabricação de cada queijo foi estimado de três maneiras, de acordo com Furtado (2005):

- Rendimento econômico: litros de leite necessários para a elaboração de um quilo de queijo (L/kg). Neste caso, dividiu-se o volume de leite empregado pela soma da massa dos queijos obtidos;

- Rendimento ajustado para umidade: produção ajustada para um mesmo teor de umidade. Nesse caso o teor de umidade utilizado foi de $55 \%$ para o queijo Minas Frescal e de 
- Em gramas de sólidos totais do queijo por litro de leite (g ST/L);

\section{Análise estatística}

Os resultados obtidos foram tabulados em planilhas do Excel e submetidos as seguintes análises estatísticas descritivas: média aritmética, valor mínimo, valor máximo e desvio padrão.

\section{RESULTADOS E DISCUSSÃO}

Os valores médios, desvios padrões, máximos e mínimos da composição centesimal, densidade e acidez do leite cru dos produtores que forneceram leite para o laticínio no período de estudo constam na Tabela 1. Na mesma Tabela, são verificados os padrões legislados pela Instrução Normativa $\mathrm{N}^{\circ} 76$ (Brasil, 2018).

Tabela 1. Análise individual da composição centesimal, densidade e acidez do leite cru destinados ao beneficiamento do laticínio durante o período de coleta (média obtida da análise individual de dez produtores)

\begin{tabular}{lccccc}
\hline \multicolumn{1}{c}{ Variáveis } & Média & SD & Mín. & Máx. & Padrões \\
\hline Gordura, \% & 4,10 & 0,26 & 2,83 & 6,23 & Mín 3,0* \\
Proteína, \% & 3,59 & 0,05 & 3,37 & 3,87 & Mín 2,9* \\
EST, \% & 12,26 & 0,39 & 10,71 & 14,95 & Mín $11,4^{* *}$ \\
ESD, \% & 8,15 & 0,15 & 7,03 & 9,14 & Mín 8,4* \\
Lactose, $\%$ & 4,36 & 0,06 & 3,57 & 4,75 & Mín 4,3** \\
Cinza, $\%$ & 0,64 & 0,02 & 0,43 & 0,76 & - \\
Densidade, g/ml & 1,030 & 0,47 & 1,027 & 1,033 & 1,028 a $1,034^{*}$ \\
Acidez, ${ }^{\circ} \mathrm{D}$ & 18 & 0,70 & 15 & 20 & 14 a $18^{*}$ \\
\hline$N$ & 290 & & & & \\
\hline
\end{tabular}

EST= Extrato Seco Total; ESD= Extrato Seco Desengordurado; * valores mínimos preconizados pela Instrução Normativa $\mathrm{N}^{\circ} 76$, de 26 de novembro de 2018; ** valores mínimos preconizados pelo Regulamento da Inspeção Industrial e Sanitária de Produtos de Origem Animal (RIISPOA, 2017); SD= Desvio padrão, Mín= Mínimo; Máx= Máximo; $n=$ número de amostras de leite cru análises.

Os resultados médios obtidos para os teores de gordura, proteína, extrato seco total, lactose, densidade e acidez do leite cru, atendem os requisitos mínimos estabelecidos pela IN 76. Entretanto, o ESD não atende o valor mínimo de 8,4\% estabelecido pela IN 76. A média do ESD verificada nesse estudo foi de $8,15 \%$. Quando analisado a média individual de cada produtor, verifica-se que apenas um produtor atendeu o teor mínimo de ESD preconizado pela legislação. Portanto, pode-se concluir que o baixo teor de ESD é um problema recorrente entre os produtores que fornecem leite para o laticínio.

Vários fatores podem influenciar sobre o teor de ESD do leite cru, entre eles pode-se 


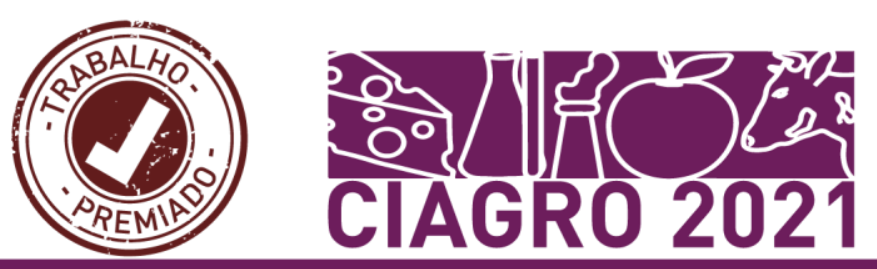

citar a nutrição animal e os fatores genéticos. No geral, o rebanho das propriedades que fornecem leite para o laticínio, são constituídos por animais sem aptidão leiteira, isso pode ser justificado pelo fato dos produtores criarem animais com aptidão para carne. Além disso, a maior parte dos sistemas de criação são manejados de forma extensiva, com forragem de baixa qualidade e disponibilidade, fator que influencia a relação de energia e proteína disponibilizada aos animais, e consequentemente influencia na produção de proteína microbiana que vai ser disponibilizada no intestino na forma de aminoácidos, e este será necessário para síntese de proteína do leite.

Considerando que o teor de proteína do leite encontrado nesse estudo está dentro do preconizado pela legislação, mesmo quando se observa o valor mínimo obtido. Então, pode-se sugerir que o fator limitante para o baixo teor do ESD não foi a proteína. Por outro lado, quando se observar a lactose verifica-se que o valor mínimo encontrado foi de $3,57 \%$, sendo que o valor mínimo preconizado pela IN 76 é de 4,3\%. Conferindo dessa forma, a possível causa do baixo teor de ESD.

A lactose além de ser o principal açúcar do leite é responsável pelo volume total do mesmo, podendo ser influenciada pelos níveis de glicose sanguínea, sendo esta oriunda da gliconeogênese hepática e tem como o principal percussor o propionato. Sendo este oriundo da fermentação dos carboidratos altamente fermentáveis da dieta das vacas (SANTOS e FONSECA, 2007). Entretanto o baixo teor da lactose pode ser em função da não suplementação de concentrado para os rebanhos. No entanto, a lactose não é considerada um problema para a produção dos queijos.

Outra possível explicação para o baixo ESD é a adição de água no leite, porém, a análise de densidade que é um indicativo de adulteração do leite pela adição de água, mostra-se dentro do padrão estabelecido pela legislação. Portanto, a genética e a nutrição animal são os fatores que podem melhor explicar esse baixo teor de extrato seco desengordurado.

Ressalta-se que valores inferiores de ESD podem implicar em menor rendimento de produção de queijo, desde que o principal fator limitante seja a proteína, pois a mesma desempenha um papel fundamental na formação da rede tridimensional da coalhada, sendo a principal responsável em reter os demais nutrientes do leite no queijo GOMES et al., 2010).

De acordo com Silva et al., (2017) em seu estudo sobre a caracterização físico-química e as possíveis fraudes do leite in natura comercializado informalmente no município de Aparecida/PB, encontrou $62,5 \%$ das amostras analisadas para ESD fora dos padrões recomendados pela legislação brasileira. O valor máximo observado nesse estudo para acidez foi de $20^{\circ} \mathrm{D}$ estando fora do padrão, porém esse valor não é comum entre as amostras analisadas 


\section{diariamente, sendo pontual em apenas 4 produtor. Isso provavelmente pode estar relacionado}

com contaminação de microrganismo, pois as condições de ordenha das propriedades fornecedoras de leite ainda são precária de higiene, além da deficiência de refrigeração e tempo prolongado de estocagem do leite até o laticínio em estudo.

Outro fator que pode ter influenciado na elevada acidez é a mistura do leite bovino com leite bubalino, uma vez que o leite bubalino é aceitável acidez máxima de $20^{\circ} \mathrm{D}$. Para Tronco (2008) a titulação da acidez é indispensável na inspeção industrial e sanitário do leite e derivados, pois permite avaliar o estado de conservação e eventuais anormalidades do produto.

Quanto ao teor de cinza encontrado nesse estudo corroboram com os resultados encontrados por Silva et al., (2017), onde obtiveram uma variação de cinzas de 0,45\% a 0,74\%. De acordo com Tronco (2008), os componentes minerais representam cerca de 0,60 a $0,80 \%$ do peso total do leite, sendo o cálcio o principal mineral.

Os resultados da contagem bacteriana total das amostras de leite cru de 10 produtores que abasteciam o laticínio, assim como do leite de conjunto, coletado diretamente do tanque de fabricação de queijo estão detalhados na Tabela 2. Ressalta-se que em razão da inconstância do fornecimento de leite pelos produtores, não foi possível realizar as quatro coletas de leite da maior parte dos produtores como preconizava o estudo.

Tabela 2. Contagem bacteriana total do leite cru de 10 produtores e do tanque de fabricação de queijo.

\begin{tabular}{|c|c|c|c|c|c|}
\hline \multirow{2}{*}{ PRODUTORES } & \multicolumn{4}{|c|}{ COLETAS } & \multirow{2}{*}{$\begin{array}{c}\text { IN 76* } \\
\text { Máx }\end{array}$} \\
\hline & $\mathrm{C} 1$ & $\mathrm{C} 2$ & C3 & $\mathrm{C} 4$ & \\
\hline $\mathrm{A}$ & $1,0 \times 10^{6}$ & - & - & - & \\
\hline B & $2,7 \times 10^{5}$ & - & $3,7 \times 10^{7}$ & $1,3 \times 10^{4}$ & \\
\hline $\mathrm{C}$ & $2,4 \times 10^{4}$ & $4,0 \times 10^{5}$ & $1,9 \times 10^{5}$ & - & \\
\hline $\mathrm{D}$ & $7,4 \times 10^{5}$ & - & - & - & \\
\hline E & $1,1 \times 10^{5}$ & - & $2,6 \times 10^{6}$ & $7,7 \times 10^{6}$ & \\
\hline $\mathrm{F}$ & $2,2 \times 10^{3}$ & $1,0 \times 10^{5}$ & $6,3 \times 10^{4}$ & $2,5 \times 10^{5}$ & $9.0 \times 10^{5}$ \\
\hline $\mathrm{G}$ & $3,2 \times 10^{4}$ & $6,4 \times 10^{4}$ & $4,0 \times 10^{5}$ & $4,1 \times 10^{6}$ & \\
\hline $\mathrm{H}$ & $3,8 \times 10^{5}$ & $7,4 \times 10^{4}$ & - & $3,7 \times 10^{5}$ & \\
\hline I & $3,1 \times 10^{3}$ & $8,3 \times 10^{4}$ & $8,3 \times 10^{4}$ & - & \\
\hline $\mathrm{J}$ & - & $1,4 \times 10^{4}$ & $1,1 \times 10^{4}$ & $8,3 \times 10^{3}$ & \\
\hline TANQUE & $9,6 \times 10^{4}$ & - & $1,1 \times 10^{6}$ & $1,9 \times 10^{6}$ & \\
\hline
\end{tabular}

C1, C2, C3, C4= número de coletas; IN*= Valor máximo de contagem bacteriana total no leite estabelecido pela Instrução Normativa $\mathrm{N}^{\circ} 76$, de 26 de novembro de 2018; (-) = amostras perdidas; Máx= Máximo.

Pode-se verificar que $100 \%$ das amostras avaliadas para CBT encontraram-se dentro do padrão estabelecido pela IN 76, que preconiza um valor máximo de $900.000 \mathrm{UFC} / \mathrm{ml}$. Os valores da composição centesimal, pH e ácido lático de cinco lotes de queijos Minas Frescal e de Coalho fabricados no laticínio durante o período do estudo, constam nas Tabelas 3 e 4. 
Tabela 3. Composição centesimal, pH e percentagem de ácido lático de cinco lotes de queijo Minas Frescal fabricados.

\begin{tabular}{llllllll}
\hline \multirow{2}{*}{ Variáveis } & \multicolumn{7}{c}{ Lotes de produção de queijo Minas Frescal } \\
\cline { 2 - 8 } & Lote 1 & Lote 2 & Lote 3 & Lote 4 & Lote 5 & Média & SD \\
\hline Proteína, \% & 20,43 & 20,22 & 19,93 & 21,66 & 19,89 & 20,43 & 0,72 \\
Gordura, \% & 24,00 & 24,5 & 25,50 & 24,00 & 26,50 & 24,90 & 1,08 \\
MGEST, \% & 54,01 & 53,02 & 52,57 & 49,20 & 55,36 & 52,83 & 2,30 \\
Umidade, \% & 55,56 & 53,79 & 51,49 & 51,22 & 52,13 & 52,84 & 1,82 \\
ESD, \% & 20,44 & 21,71 & 23,01 & 24,78 & 21,37 & 22,26 & 1,68 \\
Cinzas, \% & 2,32 & 3,75 & 3,18 & 3,40 & 3,24 & 3,18 & 0,53 \\
pH & 7,17 & 6,96 & 6,92 & 6,90 & 6,88 & 6,97 & 0,12 \\
Ácido lático & 0,50 & 0,54 & 0,41 & 0,45 & 0,45 & 0,47 & 0,05 \\
\hline
\end{tabular}

MGEST= Matéria Gorda no Extrato Seco Total; EST=Extrato Seco Total; ESD= Extrato Seco Desengordurado; $\mathrm{SD}=$ Desvios padrões.

Diante das análises para matéria gorda no EST e umidade do queijo Minas Frescal descritas na Tabela 3, ambas não atendem os requisitos estabelecidos pela Instrução Normativa 04/2004 (Regulamento Técnico de Identidade e Qualidade de queijo Minas Frescal), que preconiza teores de MGEST entre 25,0\% a 44,9\% e teores de umidade iguais ou acima de 55\%, classificando, portanto, o queijo Minas Frescal como semi-gordo e com muita alta umidade. Portanto, o queijo Minas Frescal produzidos no laticínio foi caracterizado como um queijo gordo, com teores de média umidade.

O fato do teor da MGEST está acima do recomendado pode ser justificado pela falta de padronização da gordura do leite utilizado na produção dos queijos do laticínio, ou seja, o laticínio utiliza leite integral para o processamento dos queijos. A não padronização do leite acarreta na produção de queijo despadronizado no quesito gordura, o que implica em prejuízos para o consumidor e para a indústria. Para o consumidor, possivelmente o rótulo nutricional do produto estará em desacordo, consequentemente, pessoas que necessitam restringir consumo de gordura e utilizam o rótulo nutricional do produto para se guiar, podem ser prejudicados nutricionalmente.

Para a indústria, o excesso de gordura nos queijos poderia ser utilizado na produção de manteiga, uma vez que, a mesma é um produto bastante valorizado no mercado, e dessa forma, os proprietários poderiam está ganhando uma renda extra na produção.

Em relação ao baixo teor de umidade, pode-se atribuir o fato dos queijos produzidos terem sido aquecidos após a primeira mexedura. Ressalta-se que na tecnologia de produção descrito por Furtado (1994) e utilizada por uma parcela considerada de laticínios em várias regiões do Brasil não é realizado aquecimento durante o processo de mexedura. Entretanto, no laticínio essa etapa é utilizada, pois a elevação da temperatura proporciona maior dessoragem, consequentemente um queijo menos úmido. O laticínio adotava essa prática como estratégia, 


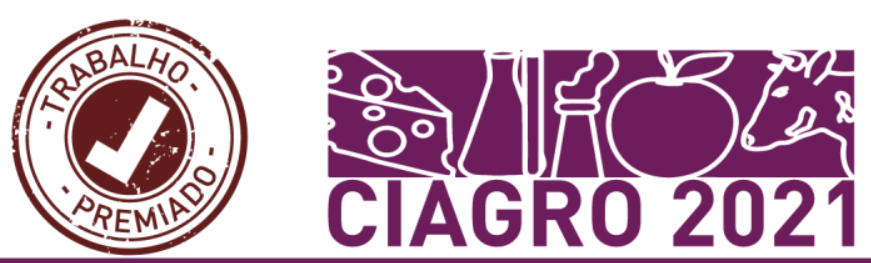

pois a cidade de Parintins tem elevada temperatura ambiente e com isso proporcionaria uma maior dessoragem nos expositores do mercado, pois os mesmos não são fechados e também não atendem as temperaturas recomendadas para conservação do produto. Caso os queijos fossem produzidos com elevada umidade, acarretaria em produtos com elevada dessoragem na embalagem, o que acarretaria em produto visualmente não agradável.

Os teores de proteína encontrados nesse trabalho corroboram com os resultados encontrados por Sangaletti et al., (2009), em estudo sobre a vida útil do queijo Minas Frescal. Por outro lado, Gomes et al., (2010), encontraram teor de 14,98\% para proteína em estudo sobre a composição centesimal do queijo Minas Frescal tradicional elaborado com coagulante microbiano.

$\mathrm{O}$ pH médio obtido nesse estudo para o queijo Minas Frescal foi de 6,97. Valor semelhante encontrado por Dias et al., (2016) e Sangaletti et al., (2009) em estudo com qualidade físico-química de queijo Minas Frescal tradicional.

Os valores de acidez titulável encontrado nesse estudo foi comparado com os valores médios dos trabalhos de Ricardo et al., (2011) que obtiveram valores de 0,68\%; Machado et al., (2004) de 0,28\% e Campos (2000) de 0,40\% em estudo com o queijo Minas Frescal. Dessa forma, verifica-se que há uma grande divergência entre os trabalhos. Isso possivelmente pode ser atribuído às diversas técnicas aplicadas na fabricação, como por exemplo, o uso de fermento lático ou de ácido lático. No entanto, o laticínio não usava nenhum desses ingredientes, porém fazia uso do bioprotetor, que possivelmente pode ser o responsável pelo elevado teor de ácido lático nos queijos.

Tabela 4. Composição centesimal, $\mathrm{pH}$ e percentagem de ácido lático de cinco lotes de queijo de Coalho fabricados.

\begin{tabular}{llllllll}
\hline \multirow{2}{*}{ Variáveis } & \multicolumn{7}{c}{ Lotes de produção de queijo de Coalho } \\
\cline { 2 - 8 } & Lote 1 & Lote 2 & Lote 3 & Lote 4 & Lote 5 & Média & SD \\
\hline Proteína, \% & 22,23 & 22,40 & 24,27 & 22,71 & 23,60 & 23,04 & 0,87 \\
Gordura, \% & 25,00 & 26,00 & 28,00 & 26,00 & 28,00 & 26,60 & 1,34 \\
MGEST, \% & 50,83 & 49,37 & 52,11 & 50,52 & 50,74 & 50,71 & 0,98 \\
Umidade, \% & 50,82 & 47,34 & 46,26 & 48,54 & 44,82 & 47,55 & 2,28 \\
ESD, \% & 24,18 & 26,66 & 25,74 & 25,46 & 27,18 & 25,85 & 1,15 \\
Cinzas, \% & 2,96 & 3,99 & 3,78 & 4,07 & 4,27 & 3,81 & 0,51 \\
pH & 6,86 & 6,98 & 6,50 & 6,87 & 6,79 & 6,80 & 0,18 \\
Ácido lático & 0,45 & 0,45 & 0,36 & 0,45 & 0,72 & 0,49 & 0,14
\end{tabular}

MGEST = Matéria Gorda no Extrato Seco Total; EST=Extrato Seco Total; ESD= Extrato Seco Desengordurado; $\mathrm{SD}=$ Desvios padrões.

É possível observar que os teores de MGEST e umidade estão de acordo com a Instrução Normativa $N^{\circ} 30$ (Regulamento Técnico de Identidade e Qualidade de queijo de Coalho), que preconiza valores entre $45 \%$ a 59,9\% para MGEST e 46\% e 54,9\% para umidade, classificando 


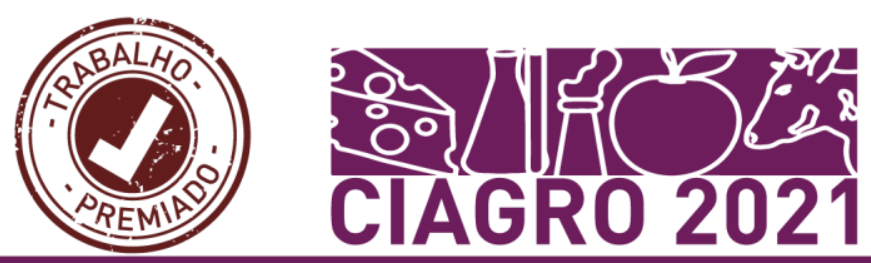

assim o queijo com gordo e de alta umidade. Dessa forma, os resultados médios encontrados nesse estudo foram de 50,71\% e 47,55\% para MGEST e umidade, respectivamente. Esses resultados corroboram com os obtidos por Gomes et al., (2012) e Silva et al., (2010), que classificam o queijo de coalho produzidos no Ceará como gordo e de alta umidade.

O resultado médio encontrado nesse estudo para o teor de gordura foi de $26,60 \%$, corroborando com o resultado encontrado por Gomes et al., (2012), que obteve um teor médio de $27,30 \%$ para queijo de coalho. O teor médio de proteína obtido dos lotes de queijo Coalho foi de 23,04\%, estando próximo do valor médio verificado por Freitas et al., (2011) em estudo sobre avaliação físico-química de queijo Coalho produzidos no estado da Paraíba.

A acidez titulável, expressa em percentual de ácido lático, variou de 0,36 a 0,72\%, concordando com os valores encontrados por Silva et al., (2010), que analisando a influência dos procedimentos de fabricação nas características físico-químicas do queijo coalho constataram valores médios de 0,40\% para acidez. Já Santos et al., (2008), detectaram valor médio de acidez de $0,66 \%$. A possível causa da elevada acidez pode está relacionada com uso do bioprotetor na fabricação dos queijos.

Os valores de pH entre os lotes de queijo coalho estudados variaram de 6,50 a 6,98, constatando-se que os queijos são frescos, recém processados. Vidal (2011), encontraram uma variação de 6,51 a 6,90 de $\mathrm{pH}$ em estudo sobre diagnóstico do processamento de queijo de coalho comercializado em Nata/RN. Por outro lado, Cavalcante et al., (2007) encontraram um valor médio para $\mathrm{pH}$ de 5,29 para as amostras de queijo de coalho processados com culturas láticas endógenas.

Os dados de perdas de proteínas e gordura no soro, rendimento econômico, rendimento ajustado e o coeficiente GL obtidos dos queijos Minas Frescal e de Coalho estão dispostos nas Tabelas 5 e 6.

Tabela 5. Perdas dos principais nutrientes, rendimento econômico, rendimento ajustado e coeficiente GL do queijo Minas Frescal.

\begin{tabular}{lccccccc}
\hline \multirow{2}{*}{\multicolumn{1}{c}{ Parâmetros }} & \multicolumn{7}{c}{ Lotes de produção de queijo Minas Frescal } \\
\cline { 2 - 8 } & Lote 1 & Lote 2 & Lote 3 & Lote 4 & Lote 5 & Média & SD \\
\hline Perda de proteínas, \% & 28,14 & 26,81 & 22,70 & 28,43 & 21,00 & 25,42 & 3,36 \\
Perda de gordura, \% & 12,50 & 9,52 & 9,76 & 16,67 & 12,20 & 12,13 & 2,88 \\
Rend. Econ. (L/Kg) & 7,14 & 6,36 & 6,82 & 7,89 & 6,69 & 6,98 & 0,58 \\
Rend. Ajustado & 6,75 & 6,02 & 6,45 & 7,46 & 6,36 & 6,54 & 0,54 \\
Coeficiente GL & 62,22 & 75,48 & 77,62 & 67,80 & 76,93 & 71,17 & 6,66 \\
\hline
\end{tabular}

Econ.=Econômico; Coeficiente GL = gramas de sólidos totais por litro de leite (g de ST/L); Rend.= Rendimento; $\mathrm{SD}=$ Desvios padrões.

Nota-se que o valor médio das perdas de gordura de $12,13 \%$ diverge com o resultado encontrado por Costa Junior (2006), que relata uma perda de 18,40\% para gordura. Por outro 
lado, esse mesmo autor avalia a perda de proteína e o resultado encontrado corrobora com esse trabalho, sendo de 25,22\%, ao passo que nesse estudo foi de 25,42\%. Ambas as perdas encontradas nesse estudo podem ser explicadas por diferenças que geralmente aconteciam durante o corte e a mexedura da coalhada. Isso confirma-se quando observa-se os lotes de produção do queijo em estudo, pois os mesmo apresentam-se bastantes heterogêneos.

Ressalta-se ainda que a qualidade do leite utilizado nos processos de elaboração desses lotes de produção está dentro dos requisitos mínimos estabelecidos pela IN 76, fato esse que poderia ser uma das causas da heterogeneidade entre os lotes. Outras possíveis causas pode ser o baixo teor de umidade dos queijos Minas Frescal encontrado nesse estudo ou o não uso do ácido lático, uma vez que quanto menor umidade maior será a perda dos nutrientes juntamente com a água. Portanto, as etapas de fabricação e o baixo teor de umidade podem ser possivelmente responsáveis pela maior perda de proteína e gordura no soro.

Tabela 6. Perdas dos principais nutrientes, rendimento econômico, rendimento ajustado e coeficiente GL do queijo de Coalho.

\begin{tabular}{lccccccc}
\hline \multirow{2}{*}{ Parâmetros } & \multicolumn{7}{c}{ Lotes de produção de queijo de Coalho } \\
\cline { 2 - 8 } & Lote 1 & Lote 2 & Lote 3 & Lote 4 & Lote 5 & Média & SD \\
\hline Perda das proteínas, \% & 25,02 & 25,38 & 27,56 & 22,75 & 25,67 & 25,27 & 1,72 \\
Perda da gordura, \% & 15,38 & 13,16 & 15,00 & 9,30 & 14,63 & 13,50 & 2,49 \\
Rend. Econ. (L/Kg) & 8,00 & 8,22 & 8,11 & 7,69 & 8,57 & 8,23 & 0,33 \\
Rend. Ajustado & 7,57 & 8,32 & 8,38 & 7,61 & 9,09 & 8,15 & 0,63 \\
Coeficiente GL & 61,48 & 64,07 & 66,28 & 66,90 & 64,38 & 63,73 & 2,08 \\
\hline
\end{tabular}

Econ.=Econômico; Coeficiente GL = gramas de sólidos totais por litro de leite (g de ST/L); Rend.= Rendimento; $\mathrm{SD}=$ Desvios padrões.

Ao observar os valores médios das perdas de proteína de 25,27\% e gordura de 13,50\% do queijo de Coalho pode-se dizer que elas corroboram com outros estudos já realizados para esse queijo. Pois, quando observa-se a composição centesimal do soro, percebe-se um valor médio de 0,54\% para gordura e 1,03\% para proteína. Machado et al., (2011) em estudo sobre a viabilidade tecnológica do uso de ácido lático na elaboração de queijo de coalho encontrou um teor de $0,52 \%$ de gordura no soro. Para Munck (2006), considera-se normal a perda de 0,3 a $0,5 \%$ de gordura e 0,7 a $0,8 \%$ de proteína no soro de queijos, sendo que esses valores não correspondem com os encontrados nesse trabalho.

A possível causa da maior perda de proteína e gordura no soro dos lotes de queijo de Coalho pode ser justificada pelo fato do mesmo ser considerado um queijo com menor teor de umidade, sendo que para isso, se faz necessário uma maior dessoragem do queijo, e consequentemente há uma perda de nutrientes junto com a água. Além disso, pode-se verificar que os processos de fabricação como o corte, a mexedura e o tamanho dos grãos não foram tão eficientes na produção dos queijos. 
Observa-se que o valor médio do rendimento econômico foi de 6,98 para o queijo Minas

Frescal e 8,23 para o de Coalho, ambos mostram-se bastante rentáveis para produção. Bragança e Souza (2016), afirmam que o queijo Minas Frescal apresenta um bom rendimento econômico, variando de 6,0 a 6,5 litros/Kg. Costa Junior (2006), estudando o rendimento econômico em queijo minas frescal tradicional encontrou um valor de 6,55, mostrando superior ao encontrado nesse estudo. Por outro lado, o rendimento econômico encontrado por Santos (2009) foi de 9,4 $\pm 0,6$ 1/Kg para o queijo Minas Frescal e por Machado, (2010) de 10,04 1/Kg para queijo de coalho, mostrando-se inferiores ao obtido nesse trabalho.

No entanto, quando se pretende avaliar a viabilidade econômica da produção de queijos de forma técnica, deve-se calcular o rendimento ajustado, pois o mesmo leva em consideração um mesmo teor de umidade para todos os lotes produzidos, uma vez que a mesma vai influenciar em um menor ou maior rendimento dos queijos (FURTADO, 2005). No caso desse trabalho, considerou-se um teor de $47 \%$ de umidade, e com isso obteve-se um valor médio para o rendimento ajustado de 6,54 1/Kg e 8,15 1/Kg para os queijos Minas Frescal e de Coalho, respectivamente. Machado (2010) encontrou um valor de 9,82 1/Kg para produção ajustada com teor de $46 \%$ de umidade em estudo com queijo de coalho. Entretanto, isso não é o suficiente para estimar o rendimento final do produto, assim, faz-se necessário calcular o coeficiente G/L.

O rendimento médio em g de ST/L do queijo Minas Frescal foi de 71,17 e de 63,73 para o queijo de Coalho. Isso mostra que, mesmo com as variações observadas nas perdas de proteína e gordura dos diferentes lotes dos queijos analisados, os queijos obtiveram um bom rendimento em g de ST/L em relação a outros estudos realizados com esses queijos.

O rendimento em g de ST/L observado para queijo Minas Frescal por Souza e Silva (2005) foi inferior $(65,87$ e 67,17) ao encontrado nessa pesquisa, isso deve-se ao fato da maior perda de gordura no soro, ocasionada pela utilização de leite de baixa qualidade nutricional e pela variação nas etapas de processamento relatada pelos autores.

O aproveitamento dos sólidos totais por litro de leite produzido encontrado por Machado (2010) para queijo de Coalho foi inferior (55,12 g ST/L) ao encontrado nesse estudo, isso podese atribuir as diferentes etapas de produção dos queijos e a maior perda de gordura $(15,37 \%)$ observada pelo autor.

\section{CONCLUSÕES}

Conclui-se que o baixo teor de extrato seco desengordurado do leite ocasionado pelo baixo teor de lactose não é um problema para a produção de queijos não maturados, porém 


\section{pode ser um entrave para produção de iogurte no laticínio. A elevada contagem bacteriana}

total é um problema recorrente entre os fornecedores de leite, e isso pode acarretar prejuízos produtivos e consequentemente econômicos para o laticínio. O queijo Minas Frescal está em desacordo com a legislação reguladora, pois apresentou alto teor de MGEST e umidade. As perdas de proteína e gordura no soro foram elevadas para os dois tipos de queijos estudados. O rendimento dos queijos Minas Frescal e de Coalho foram numericamente superior a outros estudos já realizados, mostrando-se que são tecnicamente rentáveis para o laticínio.

\section{REFERÊNCIAS}

ARCURI, E.F. et al. Qualidade microbiológica do leite refrigerado nas fazendas. Arquivo Brasileiro de Medicina Veterinária e Zootecnia, v.58, n.3, p.440-446, 2006.

BRAGANÇA, M. G. L.; SOUZA, C. M. Agroindústria: Processamento do leite, queijo minas frescal, meia-cura, mussarela. EMATER-MG. 2016. Disponível em: <.http://www.mg.gov.br〉. Acesso em: 20 de junho de 2018.

BRASIL. Instrução Normativa ${ }^{\circ}$ 62, de 26 de agosto de 2003. Oficializa os métodos analíticos oficiais para análises microbiológicas para controle de produtos de origem animal e água. Diário Oficial da União, Brasília, DF, 18 set. 2003. Seção 1, p. 14.

BRASIL. Ministério da Agricultura, Pecuária e Abastecimento. Departamento de Inspeção de Produtos de Origem Animal. Instrução Normativa nº 76, de 26 de novembro de 2018. Aprovar o Regulamento Técnico de Produção, Identidade e Qualidade do Leite tipo A. Diário Oficial da República Federativa do Brasil, Brasília, 2018.

BRASIL. MINISTÉRIO DA AGRICULTURA, PECUÁRIA E ABASTECIMENTO. Instrução Normativa $\mathrm{N}^{\circ}$ 04, de março de 2004. Diário oficial da União. Brasília, 5 de março de 2004.

BRASIL. MINISTÉRIO DA AGRICULTURA, PECUÁRIA E ABASTECIMENTO. Instrução Normativa $n^{\circ} 30$, de 26 de junho de 2001. Diário oficial da União. Brasília, 16 de julho de 2001.

BRASIL. MINISTÉRIO DA AGRICULTURA, PECUÁRIA E ABASTECIMENTO. Portaria $\mathrm{N}^{\circ} 146$, de 07 de março de 1996. Aprova o regulamento técnico de identidade e qualidade dos produtos láticos. Diário oficial da União. Brasília, 11 março de 1996.

CAMPOS, A. C. Efeito do uso combinado de ácido lático com diferentes proporções de fermento lático mesofílicos no rendimento, proteólise, qualidade microbiológica e propriedades mecânicas do queijo minas frescal. Dissertação (Mestrado)- Universidade Estadual de Campinas. 2000.

CARDOSO, R. R. Influência da microbiota psicrotróficas no rendimento de queijo minas frescal elaborado com leite estocado sob refrigeração. Dissertação (Mestrado em Microbiologia Agrícola) - Universidade Federal de Viçosa. 2006.

CAVALCANTE, J. F. M.; ANDRADE, N. J. et al. Processamento do queijo coalho regional empregando leite pasteurizado e cultura lática endógena. Ciência e Tecnologia de Alimentos, Campinas, 27(1): 205-214. 2007. 


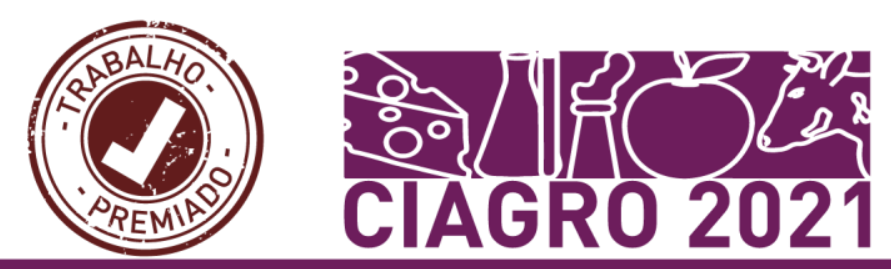

COSTA JÚNIOR, L.C. G. Uso de extensores na fabricação de queijo Minas frescal. Tese (Doutorado)- Universidade Federal de Lavras. 2006.

DIAS, B. F.; FERREIRA, S. M. et al. Qualidade microbiológica e físico-química de queijo minas frescal artesanal e industrial. Revista de Agricultura Neotropical, Cassilândia-MS, v. 3, n. 3, p. 57-64, 2016.

FAO. Food and Agriculture Organization of the United Nations. 2013.

FARIAS, A. D. A. Cadeia produtiva do leite no Amazonas: o segmento da produção de derivados. Dissertação (Mestrado em desenvolvimento Regional) - Universidade Federal do Amazonas, 2008.

FREITAS, W. C. Aspectos higiênico-sanitários, físico-químicos e microbiota lática de leite cru, queijo de coalho e soro de leite produzidos no estado da Paraíba. Tese (Doutorado em ciências e Tecnologia de Alimentos). Universidade Federal da Paraíba. 2011.

FURTADO, M. M. Principais problemas dos queijos: causas e prevenção. São Paulo. Fonte Comunicação e Editora. 200p. 2005.

FURTADO, M. M.; LOURENÇO NETO, J. P. de M. Tecnologia de queijos. São Paulo: Dipemar, 1994. 112p. Manual técnico para a produção industrial de queijos.

GOMES, J. P.; PRUDÊNCIO. S. H. et al. Queijo tipo minas frescal com derivados de soja: características físicas, químicas e sensoriais. Ciência e Tecnologia de Alimentos, Campinas, 30 (Supl.1): 77-85, 2010.

GOMES, R. A.; MEDEIROS, U. K. L. et al. Caracterização físico-química dos Queijos de Coalho artesanal e industrial comercializados na cidade de Currais Novos/RN. In: VII Congresso Norte Nordeste de Pesquisa e Inovação, Tocantins. Anais... 2012. Disponível em: $\langle$ http://propi.ifto.edu.br/ocs/index.php/connepi/vii/paper/viewFile/3305/3022>. Acesso em: 5 de abril de 2018.

INSTITUTO BRASILEIRO DE GEOGRAFIA E ESTATÍSTICA - IBGE. 2020. Disponível em: 〈http://www.ibge.gov.br >. Acesso em: 07 de maio de 2021.

MACHADO, E. C.; FERREIRA, C. L. L. F. et al. Características físico-químicas e sensoriais do queijo minas Artesanal produzido na região do serro, minas gerais. Ciência e Tecnologia de Alimentos, Campinas, 24(4): 516-521, 2004.

MACHADO, G. M. Viabilidade tecnológica do uso de ácido lático na elaboração de queijo de coalho. Dissertação (mestrado em ciência e tecnologia do leite e derivado). Universidade federal de juiz de fora. 2010.

MACHADO, G. M.; COSTA, R. G. B; PAULA, J. C. J.; PAIVA, P. H. C.; TAVEIRA, L. B.; ALMEIDA, F. A. Viabilidade tecnológica do uso de ácido lático na fabricação de queijo de coalho. Revista. Instituto de Laticínios Cândido Tostes, nº 379, 66, 1:15, 2011.

MACHADO, N. J. B.; LAUREANO, M. M. M.; MOTA, D. A.; MATOS, I. T. S. R.; BRASIL, R. J. M.; HOSHIBA, M. A. Caracterização da qualidade microbiológica do leite cru de propriedades do município Parintins-AM. Revista de ciências agrárias, v. 55, n. 4, p. 327-331. 2012. 
MELO, C. W. B. Avaliação da gestão da qualidade na empresa Viva Mais Indústria e Comércio de Laticínios LTDA. Universidade Federal da Paraíba, Bananeiras - PB, 2013.

MOTA, D. A.; JACAÚNA, A. G. et al. Caracterização da produção leiteira do município de Parintins, Estado do Amazonas, Brasil. Revista Ciências Agrárias, v. 55, n. 2, p. 148-153, 2012.

MUNCK, A. Apostila de Tecnologia de Fabricação de Queijos. Revista do Instituto de Laticínios Cândido Tostes. Juiz de Fora, 2006.

NASSU, R. T.; ANDRADE, A. S. A. et al. Caracterização físico-química de queijos regionais produzidos no Estado do Rio Grande do Norte. Revista do Instituto de Laticínios Cândido Tostes, v. 61, n. 351, p. 303-305, 2006.

PASSOS, A. D. et al. Avaliação microbiológica de queijos Minas Frescal comercializados nas cidades de Arapongas e Londrina - PR. Revista do Instituto de Laticínios Cândido Tostes, v. 64 , n. 369, p. 48-54, 2009.

RAMOS, M.T. Tipos de pasteurização e agentes coagulantes na fabricação do queijo tipo prato. Tese (Ciência dos Alimentos) Universidade Federal de Lavras, Lavras-MG. 2013.

SANGAletti, N.; PORTO, E. et al. Estudo da vida útil de queijo Minas. Ciência e Tecnologia de Alimentos, Campinas, 29(2): 262-269. 2009.

SANTANA, E. H. W.; BELOTI, V. et al. Contaminação do leite em diferentes pontos do processo de produção: I. Microrganismos aeróbios mesófilos e psicrotróficos. Seminário: Ciências Agrárias, Londrina, v. 22, n. 2, p. 145-154, 2001.

SANTOS, J. S.; SANTANA, M. M. et al. Diagnóstico das condições de processamento de produtos artesanais derivados do leite no estado de Sergipe. Revista do Instituto de Laticínios Cândido Tostes, $n^{\circ}$ 363, 63: 17-25, 2008.

SANTOS, M. V.; FONSECA, L. F. L. Estratégias para controle de mastite e melhoria da qualidade do leite. 1.ed. Barueri: Manole, 2007.

SILVA, G. W. N.; OLIVEIRA. M. P. et al. Avaliação físico-química de leite in natura comercializado informalmente no sertão paraibano. Revista principia, $n^{\circ} 25$, João Pessoa. 2017.

SILVA, M. C. D.; RAMOS, A. C. S.; MORENO, I.; MORAES, J. O. Influência dos procedimentos de fabricação nas características físico-químicas, sensoriais e microbiológicas de queijo de coalho. Revista Instituto Adolfo Lutz. 2010; 69 (2):214-21.

TRONCO, Vânia Maria. Manual para inspeção da qualidade do leite. Santa Maria: Ed. UFSM, 206p. 2008.

VIDAL, R. H. L. Diagnóstico regional do processo de queijo coalho comercializado em Natal/RN. Dissertação (Mestrado)- Universidade Federal do Rio Grande do Norte. 2011. 